\title{
Fate of Macrolide Antibiotics with Different Wastewater Treatment Technologies
}

\author{
Min Pan $\mathbb{D}$ - Pui Ching Yau
}

Received: 13 December 2020 / Accepted: 14 February 2021 / Published online: 28 February 2021

(C) The Author(s), under exclusive licence to Springer Nature Switzerland AG part of Springer Nature 2021

\begin{abstract}
This comprehensive study addressed the occurrence, seasonal changes, removal efficiencies, and environmental risk assessments of three macrolide antibiotics in five wastewater treatment plants (WWTPs) with conventional and different additional treatment processes. A 1-year monitoring study was conducted, and influents and effluents were collected from Guangzhou (GZ), Shenzhen (SZ), Tai Po (TP), Shatin (ST), and Stonecutters Island (SI) WWTPs. Solid phase extraction and HPLC-MS/MS were used for the pretreatment and determination. The detection limits for azithromycin (AZI), erythromycin (ERY), and roxithromycin (ROX) ranged from 0.80 to $2.13 \mathrm{ng} / \mathrm{L}$ for the influent and effluent water samples. AZI was the most abundant antibiotic found in the influents, with average concentrations ranging from $571 \mathrm{ng} / \mathrm{L}$ to $1046 \mathrm{ng} / \mathrm{L}$ at all the target WWTPs. The seasonal average AZI concentration was the highest in all five WWTPs with the concentration of $984 \mathrm{ng} / \mathrm{L}$ in
\end{abstract}

\footnotetext{
Highlights

- Macrolide antibiotics were monitored in five WWTPs from spring to winter

- Azithromycin was the most abundant compound found in the influent

- The seasonal changes followed a decreasing order of autumn $>$ winter $>$ summer $>$ spring

- GZ and SZ WWTPs displayed better removal rates than the other WWTPs

- Modified A2/O process has important effects on the antibiotic removal
}

M. Pan $(\bowtie) \cdot$ P. C. Yau

Faculty of Design and Environment, Technological and Higher Education Institute of Hong Kong, Hong Kong, China e-mail: liviapm@thei.edu.hk autumn, $849 \mathrm{ng} / \mathrm{L}$ in winter, $741 \mathrm{ng} / \mathrm{L}$ in summer, and $533 \mathrm{ng} / \mathrm{L}$ in spring. The seasonal AZI removal rates in the WWTPs were similar, with an average removal rate above $63.3 \%$ from spring to winter. All the treatments in the five WWTPs showed removal abilities for AZI, ERY, and ROX, regardless of the three phase treatments, namely, the UV disinfection process and conventional or chemically enhanced process within the WWTPs. For ERY and ROX, the average total removal rates were significantly decreased in the spring among all five WWTPs, at $53.1 \%$ and $57.8 \%$, respectively. The GZ and SZ WWTPs displayed better removal rates than the TP, ST, and SI WWTPs, because the activity underlying the modified A2/O process in the GZ and SZ WWTPs has important effects on the antibiotic removal because the bacteria could produce compact granules and make the antibiotics settle faster in the wastewater. The additional UV disinfection in the SZ WWTP improved the removal efficiencies of the target antibiotics; it enhanced the biodegradability of residual organic pollutants in the WWTP effluent. Moreover, the corresponding environmental risks have been assessed and are viewed as a necessary component of future research.

Keywords Antibiotics · Treatment technologies . WWTPs $\cdot$ Seasonal change

\section{Introduction}

The presence of human and animal antibiotics in the aquatic and terrestrial environment has been recognized 
as an important and vital environmental issue in recent years (Zheng et al. 2019). Macrolide antibiotics such as erythromycin, roxithromycin, and azithromycin are used widely, primarily to treat and inhibit respiratory diseases, which are largely caused by gram-positive and gram-negative pathogens. The total amount of macrolides used in China was estimated to be approximately 42,200 tons at 2013 (Zhang et al. 2015). Based on reports about the human consumption of antibiotics in Europe, macrolides accounted for $13.3 \%$ of the total sales in 2015 (ECDC 2015). In 2030, global antibiotic consumption was expected to rise up to 105,596 tons, and China would be the largest consumer of antibiotics by food-producing animals (Van Boeckel et al. 2015). Owing to the consumption and persistence of antibiotics, the bioaccumulation and unknown effects in the aquatic and terrestrial environment pose risks to the environment and human health.

After using the treatment technologies housed in wastewater treatment plants (WWTPs), the antibiotics may persist through the treatment step and be detected in effluent water and even in the subsequent receiving water or drinking water. Thus, the elimination of antibiotics by WWTPs through different treatment technologies is an important issue to ensure the quality of water supplied to cities. The removal rates of WWTPs by conventional and additional treatment technologies are subject to varying factors, e.g., secondary treatment processes, rainfall, temperature, industrial discharge, and seasonal changes. The influents and effluents from five wastewater treatment plants located in the Pearl River Delta (PRD, including Guangzhou, Shenzhen, Tai Po, Shatin, and Stonecutters Island) were collected following the application of conventional and different additional treatment technologies. The PRD is a megalopolis area; it is at the southern end of the southern coast of China. The PRD had a population of 57.15 million people in $2013,53.69 \%$ of the provincial population. The Guangzhou (GZ) wastewater treatment plant (WWTP) has three phases using different treatment methods, and it is one of the largest secondary sewage treatment plants, serving 2.26 million people in Guangdong Province. The Shenzhen (SZ) WWTP employs a combined high-efficiency sedimentation tank and UV disinfection process to treat wastewater, and it serves a population of 2.1 million in Shenzhen. Both the Tai Po (TP) and Shatin (ST) WWTPs employ conventional activated sludge processes and serve populations of 0.25 and 0.6 million in Hong Kong, respectively. The
Stonecutters Island (SI) WWTP is one of the largest and most compact sewage treatment centers of its type in the world. It serves a population of 3.5 million in Hong Kong and uses chemically enhanced primary treatment for wastewater. Long-term monitoring for antibiotics in WWTPs with different treatment technologies is needed to provide a more comprehensive summary of WWTP removal rates of target antibiotics and the seasonal effects on their concentrations in the effluents. Most WWTP monitoring studies were only undertaken in certain cities for a short time or simply used one type of treatment process, and some were limited in scope (Grandclément et al. 2017; Jing and Cao 2012; Lacey et al. 2012; Östman et al. 2019).

We aim to fill the existing gaps in our knowledge by providing a comprehensive report that will (1) compare the antibiotic concentrations obtained from different WWTPs, (2) investigate the seasonal variation of antibiotics in the influents and effluents of WWTPs, (3) evaluate the removal efficiencies of antibiotics using different treatment technologies in WWTPs, and (4) assess the environmental risks of target antibiotics in aquatic and terrestrial environments. Therefore, the results of an extensive 1-year monitoring study have been explored by sampling five WWTPs with conventional and different additional treatment technologies (influents and effluents) in the PRD region of China.

\section{Methodology}

\subsection{Chemicals}

Azithromycin (AZI), erythromycin (ERY), and roxithromycin (ROX), which are macrolides, were selected and tested in this study; their physicochemical properties can be found in Table 1. All standards and the internal standard (ERY $\left.-{ }^{13} \mathrm{C}_{2}\right)$ were obtained from Sigma-Aldrich (USA) and Toronto Research Chemicals (Canada). Oasis HLB extraction cartridges $(6 \mathrm{~mL}, 500$ $\mathrm{mg}$ ) were purchased from Waters (Waters Corporation, USA) and used for the extraction and purification. All the organic solvents used here were purchased from Merck Corporation (Germany) and were HPLC grade. Individual stock solutions of AZI, ERY, and ROX and internal standard were prepared at $100 \mathrm{mg} / \mathrm{L}$ in methanol and stored in amber glass vials at $-20^{\circ} \mathrm{C}$. Standard mixtures were mixed together with the internal standard and used as working solutions. 


\subsection{Sampling Sites and Sample Collection}

Five wastewater treatment plants (GZ, SZ, TP, ST, and SI) in the PRD region of China were chosen for sampling (Fig. 1), and the summary information was listed in Table 2. The GZ WWTP has three phases with different treatment methods. Phase I uses the adsorption-biodegradation process, phase II uses the UNITANK process (each Unitank process was divided into three tanks for feeding, agitation, aeration, and settling), and wastewater passes through the preliminary treatment and then enters each compartment in the reactor in sequence. Phase III employs modified A2/O (anoxic/anaerobic/oxic) technology in which biological phosphorus can be removed, along with simultaneous nitrification and denitrification. The SZ WWTP uses a combined high-efficiency sedimentation tank and UV disinfection process to treat wastewater in the Futian District. Wastewater samples pass the inlet screen, the outlet of the swirling grit chamber, and secondary settling tank, and the last step is the UV disinfection device. Both TP and ST WWTPs employ a conventional activated sludge process. The conventional activated sludge process includes the primary treatment (grit removal), activated sludge treatment, passage through a sludge settling tank, and finally sand filtration. The SI WWTP is one of the largest and most compact chemically enhanced sewage treatment plants in the world, occupying 10 hectares of reclaimed land. It involves chemically enhanced primary treatment, and it treats sewage collected from seven preliminary treatment plants in the primary urban areas of Kowloon and northeastern Hong Kong Island. The sewage water was collected from June 2019 to May 2020, and the process flow diagrams and sampling points in the GZ, SZ, TP, ST, and SI WWTPs are shown in Fig. S1. Hydraulic retention time (HRT) was longer than $16 \mathrm{~h}$ for secondary treatment plants (TP and ST), but only $2 \mathrm{~h}$ for primary treatment plant (SI) and not available in GZ and SZ. The exposure time for wastewater treatment generally affected the removal rate of antibiotics.

\subsection{Sample Preparation and Antibiotic Extraction}

Solid phase extraction (SPE) was applied to the influent and effluent water samples using Oasis HLB cartridges. The internal standard (100 $\mathrm{ng}$ ) and $0.2 \mathrm{~g}$ of disodium ethylenediaminetetraacetate $\left(\mathrm{Na}_{2} \mathrm{EDTA}\right)$ were spiked into each collected influent and effluent water sample.
Each SPE cartridge was preconditioned with methanol and Milli-Q water in accordance with the procedures described in our previous study (Pan et al. 2014), after which an aliquot of a water sample $(1 \mathrm{~L})$ was passed through the cartridge at a flow rate of $10 \mathrm{~mL} / \mathrm{min}$. After that, $10 \mathrm{~mL}$ of methanol was used to elute the analytes from the cartridge, and the eluates were reduced to 0.5 $\mathrm{mL}$ by a gentle nitrogen stream and then redissolved in methanol. The final extract was passed through a $0.22-\mu \mathrm{m}$ nylon syringe filter and stored at $-20{ }^{\circ} \mathrm{C}$ before the HPLC-MS/MS analysis.

\subsection{Liquid Chromatography Mass Spectrometry Analysis}

The targets, AZI, ERY, and ROX, in the WWTP influents and effluents were analyzed by high-performance liquid chromatography interfaced with tandem mass spectrometry (HPLC-MS/MS, Agilent 6410 triple quadrupole MS) that was equipped with an electrospray ionization (ESI) source in multiple reaction monitoring (MRM) mode. All three target antibiotics were analyzed in positive MRM mode. A $10-\mu \mathrm{L}$ aliquot of extract was injected onto an Agilent Eclipse XDB-C18 (3.0 × 75 $\mathrm{mm}, 3.5 \mu \mathrm{m})$ column with a poroshell 120 precolumn filter $(3.0 \mathrm{~mm}, 0.2 \mu \mathrm{m})$. The column temperature was kept at $40{ }^{\circ} \mathrm{C}$ for the analysis. The mobile phases $0.1 \%$ $(\mathrm{v} / \mathrm{v})$ formic acid (A) and acetonitrile (B) were used, under the following gradient conditions: $0 \mathrm{~min}, 5 \% \mathrm{~B} ; 5$ $\min , 40 \% \mathrm{~B} ; 8 \mathrm{~min}, 80 \% \mathrm{~B} ; 16 \mathrm{~min}, 95 \% \mathrm{~B}$, and $19 \mathrm{~min}$, $5 \% \mathrm{~B}$. The flow rates of the mobile phases were $0.3 \mathrm{~mL} /$ $\mathrm{min}$, and the mass spectrometry conditions were optimized using Optimizer (Agilent, USA) for the fine tuning of the fragmentor voltage, collision energy (CE) and MRM transitions for the AZI, ERY, and ROX. Nitrogen gas was used as the drying and collision gas. The following optimized parameters were selected: drying gas temperature $200{ }^{\circ} \mathrm{C}$, drying gas flow rate $6 \mathrm{~mL} /$ $\mathrm{min}$, and capillary voltage $4200 \mathrm{~V}$. The system was reequilibrated for $10 \mathrm{~min}$ between runs.

\subsection{Quantification and Quality Control}

The reagent and method blanks and spiked matrices were analyzed together with the influent and effluent water samples for the potential analyte loss. The internal standard was used for quantification, and the calculated relative standard deviation was used to ensure less than $10 \%$ for the analytical precision. The internal standards 
Table 1 Physicochemical properties of the antibiotics investigated in this study

\begin{tabular}{|c|c|c|c|}
\hline Compound & Azithromycin & Erythromycin & Roxithromycin \\
\hline CAS number & $83905-01-5$ & $114-07-8$ & $80214-83-1$ \\
\hline Molecular formula & $\mathrm{C}_{38} \mathrm{H}_{72} \mathrm{~N}_{2} \mathrm{O}_{12}$ & $\mathrm{C}_{37} \mathrm{H}_{67} \mathrm{NO}_{13}$ & $\mathrm{C}_{41} \mathrm{H}_{76} \mathrm{~N}_{2} \mathrm{O}_{15}$ \\
\hline Molecular weight & 748.5 & 733.46 & 836.52 \\
\hline $\log \mathrm{K}_{\mathrm{ow}}$ & 4.02 & 3.06 & 2.75 \\
\hline$p \mathrm{Ka}$ & 8.74 & 8.88 & n.a. \\
\hline Chemical structures & & & \\
\hline
\end{tabular}

and standard solutions were used to correct for the matrix effects in the water samples. The recoveries for
ERY, ROX, and AZI were $82 \pm 1 \%, 86 \pm 2 \%$, and $76 \pm$ $1 \%$ in the influent and effluent water samples,

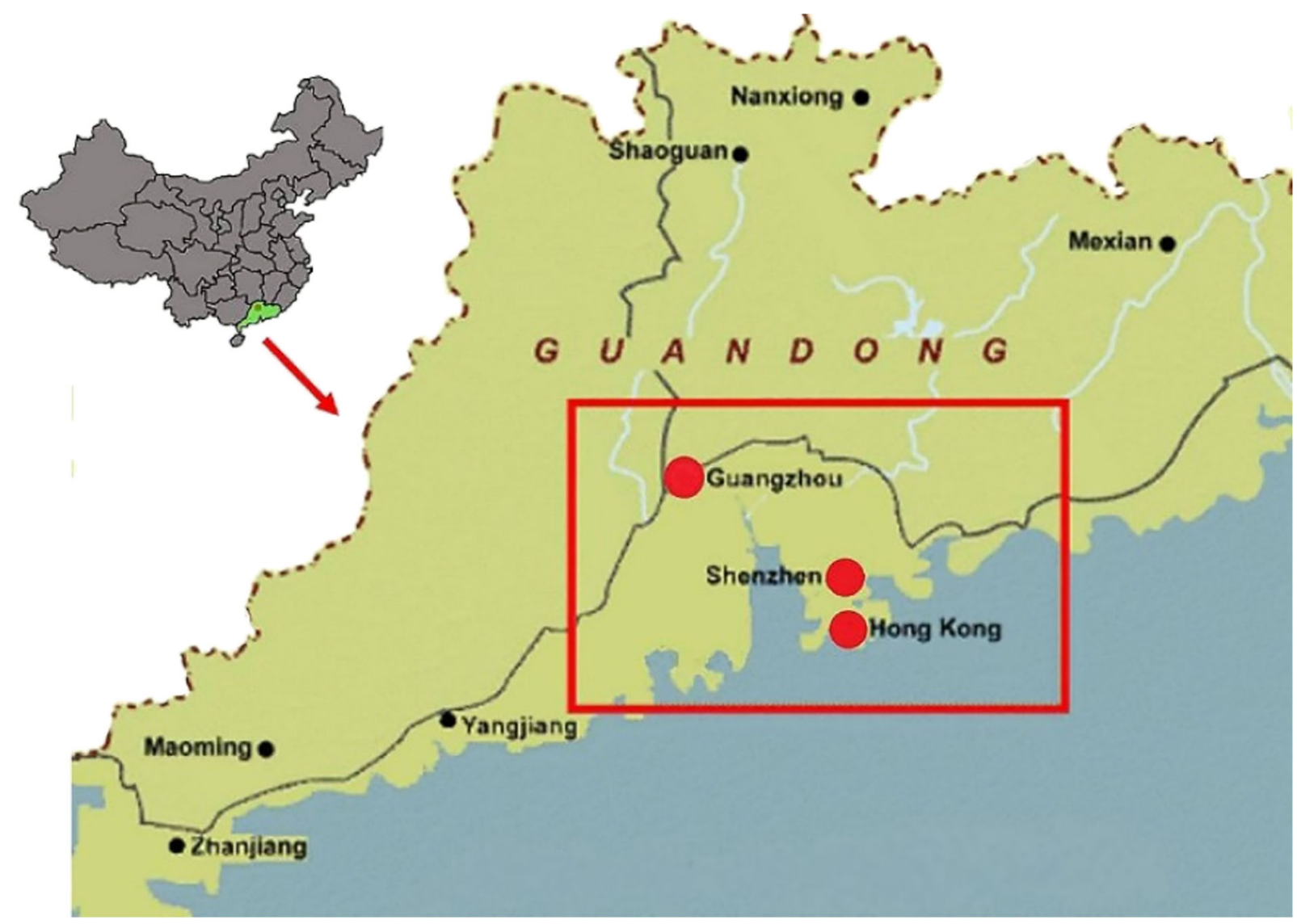

Fig. 1 Map of the sampling sites along the Pearl River Delta, southern China 
respectively. The limit of detection (LOD) and limit of quantification (LOQ) of the antibiotics were defined as 3 and 10 times the noise level in the baseline of the HPLCMS/MS, respectively. The LOQs of ERY, ROX, and AZI ranged from 0.80 to $2.13 \mathrm{ng} / \mathrm{L}$ for the influent and effluent water samples. Ten concentrations from 0.5 to $500 \mathrm{ng} / \mathrm{L}$ of individual antibiotics were used to calculate the calibration curves $\left(r^{2}>0.99\right)$.

\subsection{Statistical Analysis}

SPSS version 17.5 was used for the statistical analyses. A one-way analysis of variance (ANOVA) and Tukey's test were used to investigate the significance of the differences between different WWTPs and target antibiotic concentrations in influent and effluent water.

\section{Results and Discussion}

\subsection{Performance of the Studied WWTPs}

The performance of the five studied WWTPs was assessed by determining the removal rates of the suspended solids $(\mathrm{SS}), \mathrm{BOD}_{5}, \mathrm{COD}_{\mathrm{Cr}}$, and nutrients (Table 3). All the detected parameters (DO, $\mathrm{pH}$, water temperature, $\mathrm{SS}, \mathrm{BOD}_{5}, \mathrm{COD}_{\mathrm{Cr}}, \mathrm{TP}, \mathrm{TN}$, $\mathrm{NH}_{4}-\mathrm{N}$, and $\mathrm{NO}_{3}-\mathrm{N}$ ) met the effluent regulatory target of the PRD, in southern China. The treatment occurred through nitrification and in association with the decrease of $\mathrm{NH}_{4}-\mathrm{N}$ that caused the negative removal rate of $\mathrm{NO}_{3}$ $\mathrm{N}$ in the effluent water. The removal rates of the selected parameters are summarized in Table 3.

The WWTP operating parameters and nutrients can affect the concentration of antibiotics in the influent and effluent water samples. A good correlation was found between $\mathrm{NH}_{4}-\mathrm{N}$ and the target antibiotics in the GZ, SZ, TP, ST, and SI WWTPs $(p<0.05)$. Sabri et al. (2020) also found that $\mathrm{NH}_{4}-\mathrm{N}$ had a strong correlation with all the antibiotics and antibiotic-resistant genes during the sampling period (Sabri et al. 2020). However, no significant correlation was observed between $\mathrm{SS}, \mathrm{BOD}_{5}$, and $\mathrm{COD}_{\mathrm{Cr}}$ and the concentrations of target antibiotics. Therefore, an in-depth and full-scale study should be conducted to assess the effects of these parameters on the WWTP, unpredictable conditions, and antibiotic consumption in relation to the WWTP removal efficiencies.
3.2 Occurrence and Distribution of Target Antibiotics in the WWTPs

The occurrence and distribution of three target macrolide antibiotics in the influent and effluent water samples from five WWTPs with different treatment technologies were investigated. All three antibiotics are measured in the influent of all five target WWTPs during the sampling period from June 2019 to May 2020 (Fig. 2). The concentrations of antibiotics after different steps of five WWTPs in each month are showed in Table S1.

The AZI, ERY, and ROX concentrations ranged from 184 to $1154 \mathrm{ng} / \mathrm{L}, 102-674 \mathrm{ng} / \mathrm{L}$, and $187-706$ $\mathrm{ng} / \mathrm{L}$, respectively, in the influent of all the WWTPs from spring to winter. AZI was the most abundant antibiotic that was detected in all influents; its average concentration was $699 \mathrm{ng} / \mathrm{L}$ in GZ, $571 \mathrm{ng} / \mathrm{L}$ in SZ, 780 $\mathrm{ng} / \mathrm{L}$ in TP, $788 \mathrm{ng} / \mathrm{L}$ in ST, and $1046 \mathrm{ng} / \mathrm{L}$ in SI. It was followed by ERY in the influent, with average concentrations of $447 \mathrm{ng} / \mathrm{L}$ (GZ), $346 \mathrm{ng} / \mathrm{L}$ (SZ), $457 \mathrm{ng} / \mathrm{L}$ (TP), $475 \mathrm{ng} / \mathrm{L}$ (ST), and $582 \mathrm{ng} / \mathrm{L}$ (SI). The lowest concentration in the influent was found for ROX, with average concentrations of $288 \mathrm{ng} / \mathrm{L}$ in TP, $282 \mathrm{ng} / \mathrm{L}$ in $\mathrm{ST}$, and $309 \mathrm{ng} / \mathrm{L}$ in SI. However, in GZ and SZ WWTPs, ROX had a little bit higher concentrations than ERY, and the average concentrations were $479 \mathrm{ng} / \mathrm{L}$ in $\mathrm{GZ}$ and $538 \mathrm{ng} / \mathrm{L}$ in SZ. The seasonal concentrations in AZI, ERY, and ROX in the influents were in the decreasing order autumn $>$ winter $>$ summer $>$ spring. The seasonal average concentration for AZI in the influent was also the highest in all five WWTPs at $984 \mathrm{ng} / \mathrm{L}$ (autumn) $>849 \mathrm{ng} / \mathrm{L}$ (winter) $>741 \mathrm{ng} / \mathrm{L}$ (summer) $>$ $533 \mathrm{ng} / \mathrm{L}$ (spring). ROX showed the lowest seasonal average concentration in influents from all five WWTPs. The highest concentration in the influent was $1154 \mathrm{ng} / \mathrm{L}$ for AZI in autumn (GZ), and the lowest concentration was $102 \mathrm{ng} / \mathrm{L}$ for ERY in spring (SZ). This finding is consistent with other studies that also reported findings from the winter time, e.g., 470 to 810 $\mathrm{ng} / \mathrm{L}$ of ERY was detected in the influents of some WWTPs in Hong Kong and Shenzhen (Gulkowska et al. 2008). Other studies also showed higher concentrations of antibiotics being detected in the influents during the winter period (Diwan et al. 2013), e.g., the detection was $24.5 \%$ (USA) and $32 \%$ (Israel) higher in the winter than in the summer (Dagan et al. 2008; Suda et al. 2014). Generally, the higher concentrations of AZI, ERY, and ROX during the autumn and winter 


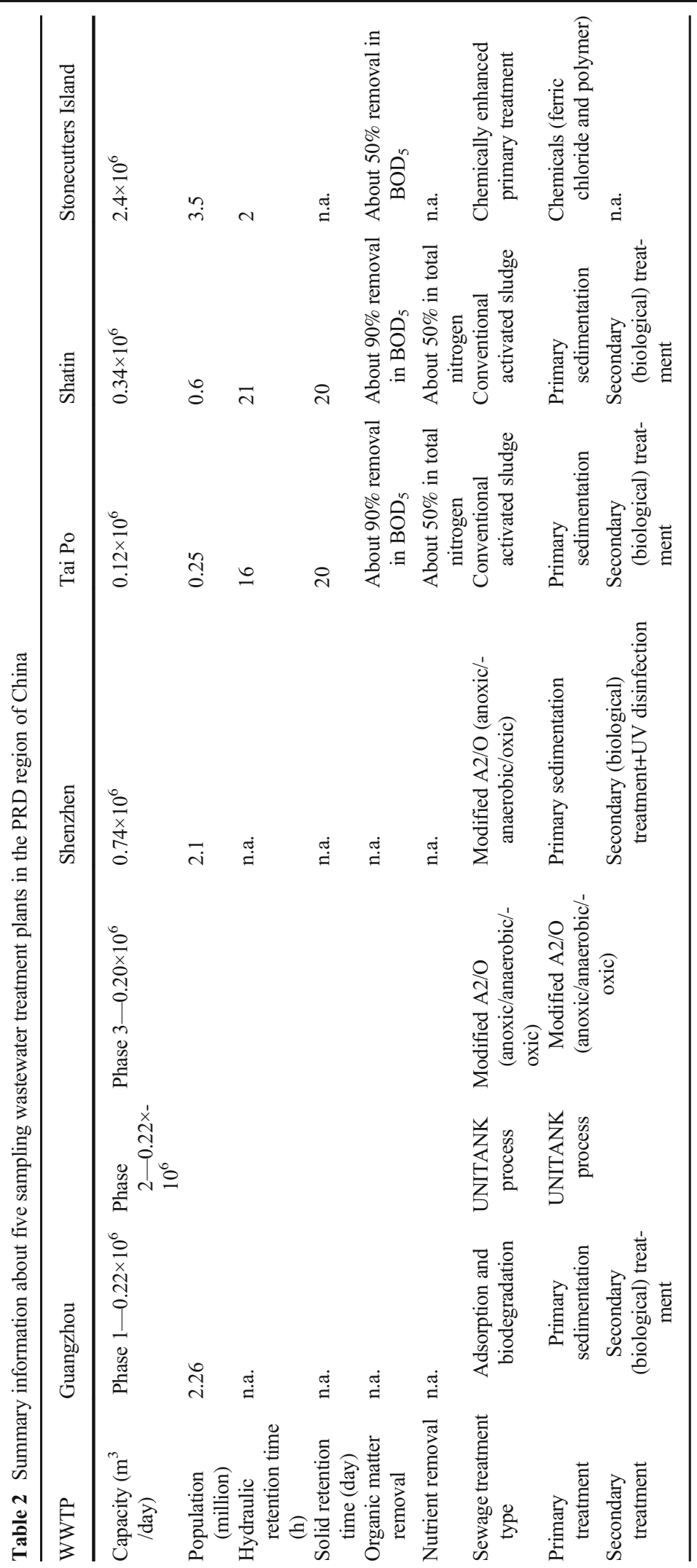


Table 3 Removal rates (\%) of selected parameters for five studied WWTPs

\begin{tabular}{|c|c|c|c|c|c|c|c|c|}
\hline & & SS & $\mathrm{BOD}_{5}$ & $\mathrm{COD}_{\mathrm{Cr}}$ & $\mathrm{TP}$ & $\mathrm{TN}$ & $\mathrm{NH}_{4}-\mathrm{N}$ & $\mathrm{NO}_{3}-\mathrm{N}$ \\
\hline \multirow[t]{3}{*}{ Guangzhou } & Phase 1 & 92.0 & 94.0 & 85.6 & 93.3 & 44.6 & 91.7 & -3400 \\
\hline & Phase 2 & 94.5 & 94.8 & 87.2 & 93.8 & 50.3 & 98.1 & 100 \\
\hline & Phase 3 & 96.6 & 95.4 & 90.4 & 96.4 & 62.4 & 98.9 & 100 \\
\hline Shenzhen & & 96.6 & 98.4 & 91.7 & 93.8 & 77.2 & 96.7 & -800 \\
\hline Taipo & & 97.1 & 97.5 & 86.6 & 80.4 & 78.8 & 81.2 & -600 \\
\hline Shatin & & 95.6 & 94.0 & 86.8 & 63.8 & 74 & 74.8 & -500 \\
\hline Stonecutters Island & & 91.9 & 82.3 & 82.7 & 70.5 & 22.1 & 58 & -250 \\
\hline
\end{tabular}

periods are a result of increased respiratory tract infections (Werner et al. 2011). The low detection of target antibiotics occurring during the spring period, especially in mainland China (GZ and SZ WWTPs), was explained by government policies. Due to the COVID-19 started at the spring at 2020 in the mainland China, the mainland government restricted the retail sale of pharmaceuticals and antibiotics during the spring period. Therefore, it may be one of the reasons why the spring period had the lowest detection level for target antibiotics in the WWTPs at GZ and SZ.
During the different WWTP technology treatments, a similar trend was observed for AZI, ERY, and ROX in all five tested WWTPs. AZI, ERY, and ROX were detected in almost all effluent samples from the GZ, SZ, TP, ST, and SI WWTPs in autumn, winter, and summer. However, ERY and ROX were not detected in the effluent from the GZ and SZ WWTPs in the spring (Fig. 2). The AZI, ERY, and ROX concentrations ranged from 163 to $376 \mathrm{ng} / \mathrm{L}, 218-428 \mathrm{ng} / \mathrm{L}$, and $105-321 \mathrm{ng} / \mathrm{L}$ in the effluents of all the WWTPs, respectively. The ERY was the most abundant antibiotic found in all the effluents, with

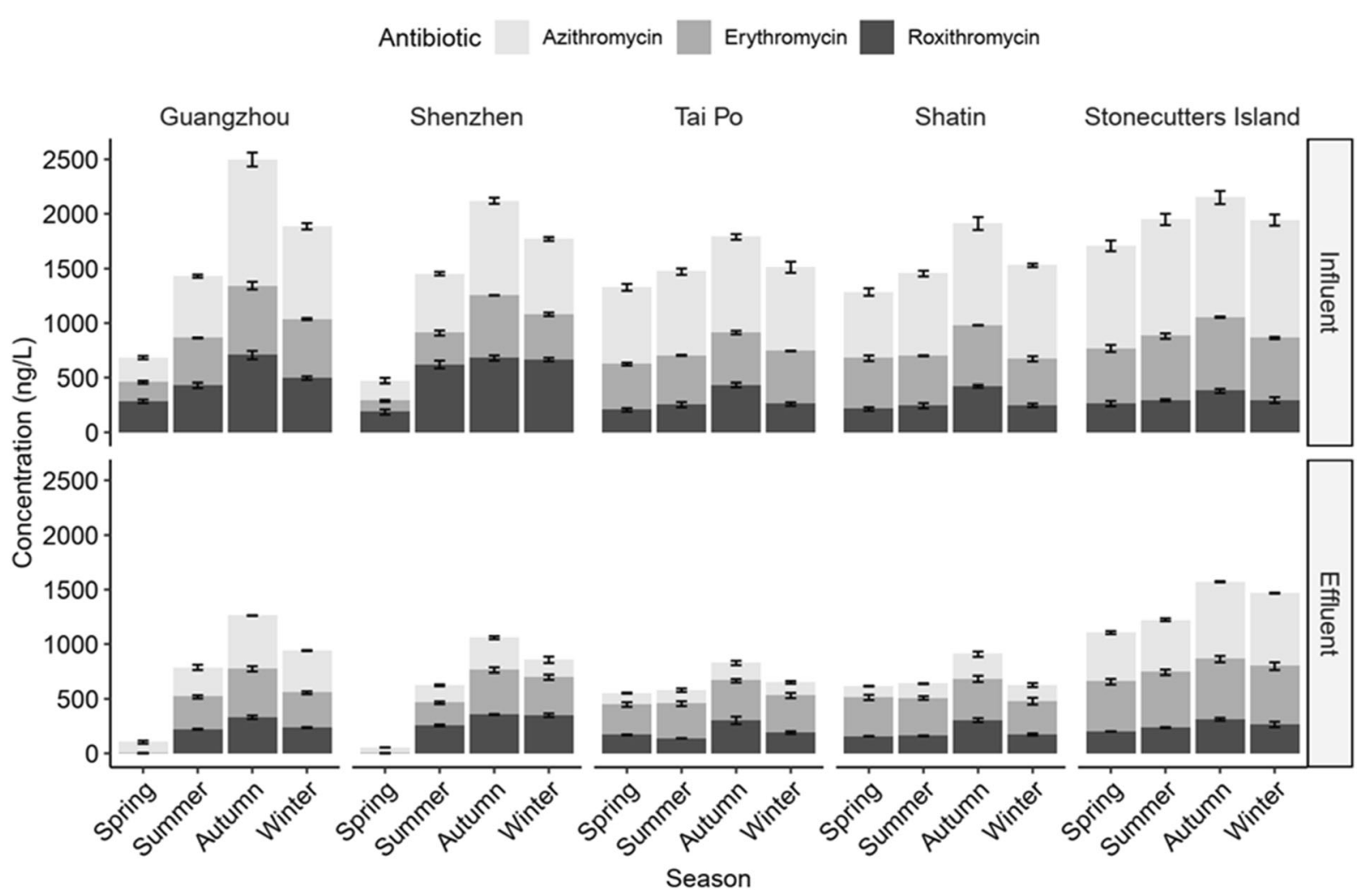

Fig. 2 Seasonal concentrations of target antibiotics in the influent and effluent of the five target WWTPs 

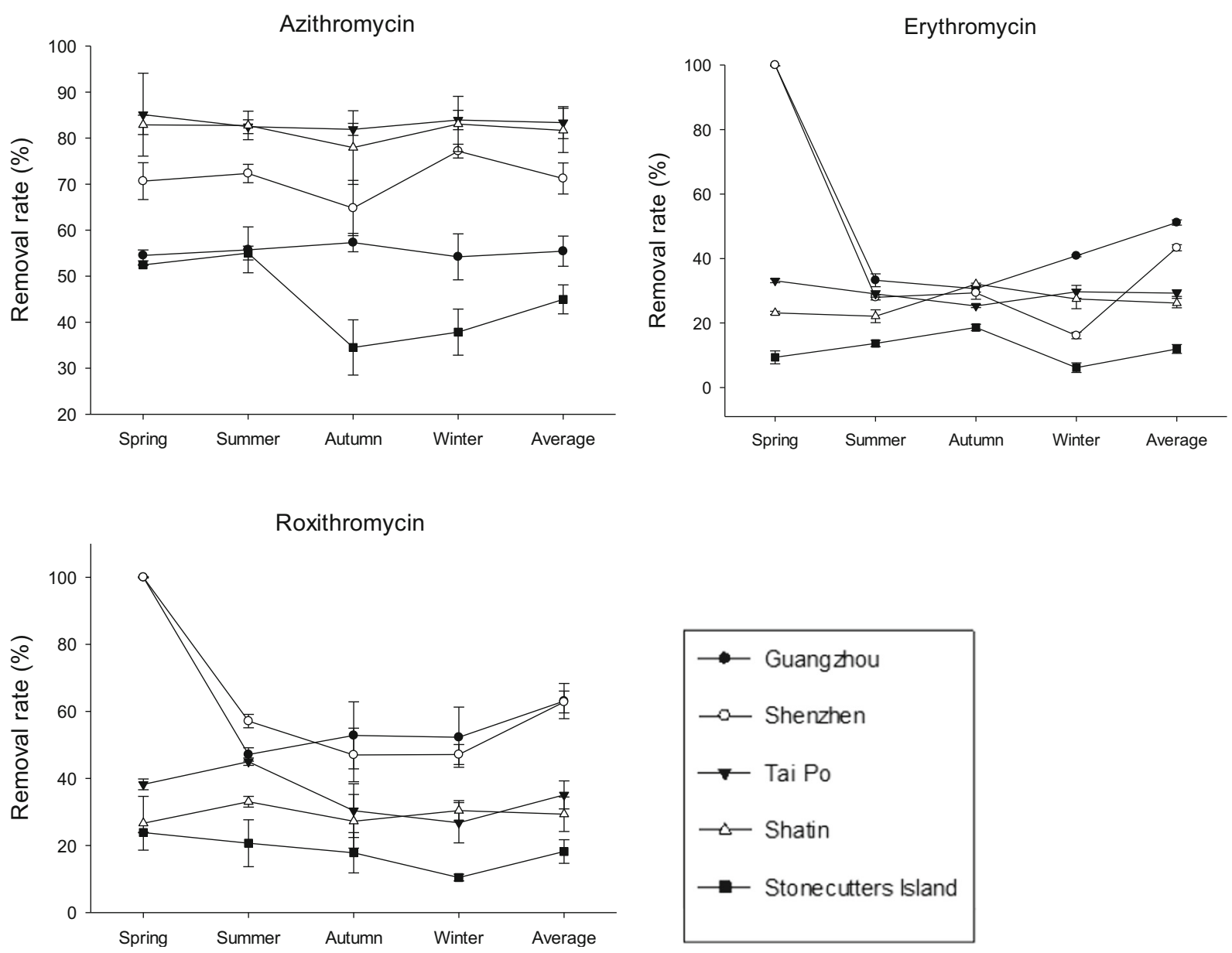

Fig. 3 Removal rates of target antibiotics by different WWTPs

average concentrations of $264 \mathrm{ng} / \mathrm{L}$ in GZ, $240 \mathrm{ng} / \mathrm{L}$ in $\mathrm{SZ}, 325 \mathrm{ng} / \mathrm{L}$ in TP, $347 \mathrm{ng} / \mathrm{L}$ in ST, and $511 \mathrm{ng} / \mathrm{L}$ in SI. Poor removal of macrolide from WWTPs was also observed by Zuccato et al. (2010) in the effluent samples from different WWTPs in Italian (Zuccato et al. 2010). This observation can be explained by the fact that ERY has a low ability to volatilize, and its $K_{d}$ is $130 \mathrm{~L} / \mathrm{kg}$, and thus it could mobilize in the sand and groundwater infiltration systems (Pan and Chu 2015). The lowest concentration in the effluent was found for ROX, with average concentrations of $197 \mathrm{ng} / \mathrm{L}$ (GZ), $241 \mathrm{ng} / \mathrm{L}$ (SZ), $200 \mathrm{ng} /$ L (TP), $199 \mathrm{ng} / \mathrm{L}$ (ST), and $254 \mathrm{ng} / \mathrm{L}$ (SI). The seasonal changes in the AZI, ERY, and ROX in the effluent also followed a decreased order of autumn $>$ winter $>$ summer $>$ spring. The seasonal average concentration was determined for ERY in the effluents that also showed the highest result in all five WWTPs of $428 \mathrm{ng} / \mathrm{L}$ (autumn) $>369 \mathrm{ng} / \mathrm{L}$ (winter) > $335 \mathrm{ng} / \mathrm{L}$ (summer) > $218 \mathrm{ng} / \mathrm{L}$ (spring). The lowest seasonal average concentration was found for ROX in the effluents of all five WWTPs. The highest concentration in the effluent was determined at $549 \mathrm{ng} / \mathrm{L}$ for ERY in the autumn (SI), and no ERY and ROX were detected in the spring (GZ and SZ). Different parameters in the WWTPs with conventional or additional treatment technologies could affect the removal rates of antibiotics from the effluents, e.g., the operation conditions, biological and chemically enhanced and UNITANK treatment, the composition of wastewaters, and physicochemical properties of the studied antibiotics (Santos et al. 2013). For example, the $K_{d}$ for ERY is 130 $\mathrm{L} / \mathrm{kg}$, so it could be mobile in the sand and groundwater infiltration systems that it showed higher concentrations in the effluents. In terms of the HRT, the values ranged from not available to $21 \mathrm{~h}$ in GZ, SZ, TP, ST, and SI WWTPs. Thus, some degradation of the target AZI, ERY, and ROX in the WWTPs could be achieved within the HRT (Pan and Chu 2015; Pan and Chu 2017b). However, a slower degradation time for other 
pharmaceuticals could display low removal efficiencies under the operating HRT. Therefore, it can be concluded that the HRT is a key parameter in the antibiotic elimination rates, especially for biodegradable antibiotics.

\subsection{Seasonal Variation}

Many studies have reported that the concentrations of antibiotics in the influent and effluent of WWTPs displayed significant seasonal variations (Golovko et al. 2014; Papageorgiou et al. 2016; Pereira et al. 2015). Nevertheless, the effects of seasonal variation on the removal rates of antibiotics are not well understood. Therefore, the concentrations and the removal efficiencies of the target antibiotics studied in the spring, summer, autumn, and winter were compared to examine their seasonal pattern (Fig. 3).

Generally, the removal efficiencies of the target antibiotics were consistently high during spring and contributed to the high elimination by the WWTPs. The seasonal removal rates of AZI in the GZ, SZ, TP, ST, and SI WWTPs were similar, with average removal rates above $63.3 \%$ from spring to winter. For ERY and ROX, the average total removal rate was significantly decreased in the spring among all five WWTPs, at $53.1 \%$ and $57.8 \%$, respectively. The ERY and ROX removal rates in the GZ and SZ WWTPs could reach $100 \%$ in the spring, which was due to the restriction of retail pharmacy sales and use of antibiotics by the mainland China government during the spring period at 2020. Thus, the different seasonal variations depend on the therapeutic usage. In addition, the increased rainfall during the spring period could increase the dilution factor and lead to low concentrations of the target antibiotics in all five WWTPs. Moreover, biodegradation and sorption are two important and prevalent mechanisms for antibiotic removal in WWTPs, and they are temperature-dependent. A decreasing temperature decreased the sorption of some antibiotic and degradation processes (Lacey et al. 2012; Pan and Chu 2015; Pan and Chu 2017b). Pereira et al. (2015) reported higher mass loads of pharmaceuticals in the influent and effluent in the summer than those found in the spring. Golovko et al. (2014) also reported similar results for antibiotics during the winter period. Papageorgiou et al. (2016) reported that concentrations of some antibiotics were higher in the winter due to their use against the bacterial or other infections. The Hong Kong government did not restrict the use of antibiotics by citizens, where the antibiotic concentrations in the influents and effluents from the TP, ST, and SI WWTPs were significantly increased relative to the GZ and SZ WWTPs during the spring period.

\subsection{Antibiotic Removal by Different Treatment Technologies}

The AZI, ERY, and ROX removal efficiencies in the WWTPs with different treatment technologies were investigated by comparing their concentrations in the influents and wastewater after the treatment processes. All the treatments in these five WWTPs, including the primary, conventional, and additional treatment processes, showed removal from the total AZI, ERY, and ROX loads, regardless of the three phase treatments, namely, the UV disinfection process and conventional or chemically enhanced treatment steps within WWTPs.

First, the same primary sedimentation step was evaluated in GZ, SZ, TP, and ST, and the target antibiotic removal rates were compared. The concentrations of some antibiotics were significantly decreased after the primary treatment in some WWTPs, while others were not $(p<0.05)$. ROX experienced significant removal through the primary treatment in the GZ and SZ WWTPs, with average removal rates ranging from 40.0 to $62.2 \%$, while only 5.2 to $10.2 \%$ was removed by primary treatment of TP and ST WWTPs. The primary treatment of GZ and SZ WWTPs had similar significant removal rates for AZI and ERY $(p<0.05)$, with average values ranging from 29.5 to $55.2 \%$, whereas the average removal rates after the primary treatment of TP and ST WWTPs only ranged from 5.0 to $12.8 \%$. Therefore, even though the GZ and SZ WWTPs were processing the wastewater from more than 2.1 million people, they still had better removal rates than the TP, ST, and SI WWTPs. The primary removal mechanism in the primary sedimentation step is the sorption of target antibiotics onto colloidal matter and removal during the coagulation/flocculation/sedimentation process (Couto et al. 2019; Evgenidou et al. 2015). It has been reported that more than $87 \%$ of antibiotics can be removed during the sedimentation step, and it is an effective way to treat wastewater pharmaceuticals and antibiotics in WWTPs (Evgenidou et al. 2015).

After the primary treatment, the GZ, SZ, TP, and ST WWTPs have further secondary treatment technologies. In the GZ WWTP, there is a combination of biological processes, UNITANK, and Modified A2/O processes in 
the secondary treatment. Therefore, the total removal rates for AZI, ERY, and ROX ranged from 51.2 to $63.1 \%$ (Fig. 3). SZ WWTP had effective total removal rates for target antibiotics after the secondary treatment by biological and UV disinfection, with average rates ranging from 43.4 to $71.2 \%$. The activity of the modified A2/O process in the GZ and SZ WWTPs has important effects on the antibiotic removal because the bacteria can produce compact granules and make the antibiotics settle faster in the wastewater (Wang et al. 2019). Different bacteria in the modified A2/O process could produce extracellular polymeric substances (EPS) and influence the surface properties of the biomass and increase the antibiotic sorption (Kang et al. 2018; Światczak and Cydzik-Kwiatkowska 2018). The protein in the EPS could reportedly interact with antibiotics through hydrophobic interactions and form a stable complex that enhanced the antibiotic removal rates (Xu et al. 2013). Furthermore, the additional UV disinfection in the SZ WWTP may improve the removal efficiencies of some specific antibiotics because it enhanced the biodegradability of residual organic pollutants in the effluent of WWTPs, and the low turbidity in wastewater in spring could allow higher penetration of UV disinfection (Jing and Cao 2012). Moreover, the TP and ST WWTPs used the conventional technology in the secondary treatment that had the best AZI removal rates, with average rates of $83.4 \%$ and $81.7 \%$, respectively. However, it did not show the same efficiency for the other two antibiotics, with only approximately 26.2$29.3 \%$ and $29.3 \%-35.1 \%$ removal rates for the ERY and ROX, respectively. The activated sludge in the secondary treatment process for the TP and ST WWTPs could remove antibiotics by forming a biofilm and through physico-chemical adsorption (Östman et al. 2019). Activated carbon has effective removal rates for hydrophobic compounds with a $\log K_{\text {ow }}>4$ (Grandclément et al. 2017; NCBI 2018), and the log $K_{\text {ow }}$ for AZI is 4.02; for ERY, it is 3.06 and for ROX, it is 2.75 . Therefore, the conventional technology with activated sludge in the TP and ST WWTPs had a better removal rate for AZI than the other two antibiotics. They also have the best removal performance for AZI relative to the other WWTPs with additional treatment technologies for secondary treatment. Moreover, the lifetime and saturation of activated sludge, water flow, HRT, and the concentration of antibiotics in the influent could also influence the removal efficiencies of the WWTP. In the SI WWTP, only chemically enhanced primary treatment was applied by ferric chloride and polymer processes, with average removal rates ranging from 11.9 to $45.0 \%$ for AZI, ERY, and ROX. Chemicals (ferric chloride and polymer) are injected at the inlet into the plants at required dosages and mixed with the sewage inflow in rapid mixing chambers. The physico-chemical properties of the target antibiotics could affect the reaction and combination in the ferric chloride and polymer processes, e.g., the hydrophobicity, octanol-water partition coefficient, and dissociation constant. Therefore, the removal efficiency is quite difficult to predict because the specific operating procedures applied by the given WWTP are going to be different.

\subsection{Environmental Implications}

Owing to climate change, growing population and urbanization around the world, the demand for clean water is increasing while this resource is increasingly becoming limited. As a result, wastewater reuse could be another source to tackle this problem (Angelakis et al. 2018). However, the increasing detection of persistent organic pollutants (e.g., personal pharmaceuticals and antibiotics) and their corresponding resistance genes in wastewater is cause for concern (Hong et al. 2013). American Water Works Association (AWWA 2019) indicated that water pollution is one of the top three concerns in the water industry, following by climate change and political instability. However, there are still no legal guidelines or regulations that define the permitted levels of antibiotics or other pharmaceuticals that are allowed in the water or terrestrial environment in China.

According to the above results, AZI, ERY, and ROX are present in the influent and effluent of WWTPs. Different additional treatment technologies have different removal effects on the target antibiotics. Generally, the additional treatment technologies in the GZ and SZ WWTPs led to better removal rates for ERY and ROX, and the conventional technology in the TP and ST WWTPs had the best removal rates for AZI, with an average rate of more than $81.7 \%$. Therefore, techniques for advanced treatment during the secondary treatment processes should be chosen carefully, depending on the macro and micro pollutants targeted within a specific situation. For example, if the WWTP is built for recreational water downstream, conventional technology is not recommended for use in the secondary treatment due to its low removal rates of most of 
antibiotics. If the removal were insufficient, the retention of antibiotics or other pharmaceuticals from the wastewater would cause further impacts on the terrestrial environment and public health. In our previous paper, we also found that antibiotics could be added to agricultural soils through wastewater irrigation and result in antibiotic accumulation in plants and increased environmental risks to humans (Pan and Chu 2016; Pan and Chu 2017a; Pan and Chu 2017c; Pan et al. 2014). Different antibiotics have different accumulated parts in plant, e.g., tetracycline (TC), norfloxacin (NOR), and chloramphenicol (CAP) are more likely to accumulate in the fruit than the root, while sulfamethazine (SMZ) and erythromycin (ERY) are more easily accumulated in the roots of plants. Moreover, continual irrigation would increase the adsorption of antibiotics in the soil and the uptake by crops (Pan and Chu 2018).

\section{Conclusion}

In this study, the removal of antibiotics was studied in influent and effluent samples from five WWTPs with conventional and different additional treatment technologies. The seasonal changes in the AZI, ERY, and ROX in the influents displayed the decreasing order autumn $>$ winter $>$ summer $>$ spring. All the treatments in the respective WWTPs showed removal from the total AZI, ERY, and ROX loads, regardless of the three phase treatments, namely, a UV disinfection process and conventional or chemically enhanced processes, although differences were observed within the WWTP treatment steps. The GZ and SZ WWTPs have better removal rates than the TP, ST, and SI WWTPs. The activity of the modified A2/O process in the GZ and SZ WWTPs has important effects on the antibiotic removal because the bacteria could produce compact granules that would settle faster in the wastewater. Furthermore, the additional UV disinfection in the SZ WWTP improved the removal efficiencies of the target antibiotics; it enhanced the biodegradability of the residual organic pollutants in the WWTP effluent. Moreover, the TP and ST WWTPs used the conventional technology in the secondary treatment that had the best AZI removal rates. However, it did not show the same efficiency against the other two antibiotics. The seasonal removal rates for AZI in the GZ, SZ, TP, ST, and SI WWTPs were similar from spring to winter. For ERY and ROX, the average total removal rates were significantly decreased in the spring among all five WWTPs. The removal rates of ERY and ROX concentrations in the GZ and SZ WWTPs could reach $100 \%$ in the spring, because of COVID-19 and the Chinese government's restriction of pharmacy retail sales and use of antibiotics at Guangzhou and Shenzhen during spring period of 2020. Thus, the differing seasonal variation was dependent on the therapeutic usage, temperature, and hydraulic retention time.

This study compared the concentrations and removal efficiencies of three macrolide antibiotics in five different WWTPs, and it demonstrated that the WWTPs with additional treatment technologies have the ability to provide better antibiotic removal rates compared to conventional or chemically enhanced WWTPs. Further research is needed to determine the most suitable and efficient treatment technology for antibiotics or other pharmaceuticals in WWTPs.

Supplementary Information The online version contains supplementary material available at https://doi.org/10.1007/s11270021-05053-y.

\section{References}

Angelakis, A. N., Asano, T., Bahri, A., Jimenez, B. E., \& Tchobanoglous, G. (2018). Water reuse: from ancient to modern times and the future. Frontiers in Environmental Science. https://doi.org/10.3389/fenvs.2018.00026.

AWWA. 2019. State of the Water Industry Report. https://www. awwa.org/Portals/0/AWWA/ETS/Resources/2019 STATE\%20OF\%20THE\%20WATER\%20INDUSTRY_post.pdf

Couto, C. F., Lange, L. C., \& Amaral, M. C. S. (2019). Occurrence, fate and removal of pharmaceutically active compounds (PhACs) in water and wastewater treatment plants-A review. Journal of Water Process Engineering, 32, 100927.

Dagan, R., Barkai, G., Givon-Lavi, N., Sharf, A. Z., Vardy, D., Cohen, T., Lipsitch, M., \& Greenberg, D. (2008). Seasonality of antibiotic-resistant streptococcus pneumoniae that causes acute otitis media: a clue for an antibiotic-restriction policy? The Journal of Infectious Diseases, 197, 1094-1102.

Diwan, V., Stålsby Lundborg, C., \& T.A. J. (2013). Seasonal and temporal variation in release of antibiotics in hospital 
wastewater: estimation using continuous and grab sampling. PLoS One, 8, 68715-68715.

ECDC. 2015. Antimicrobial consumption interactive database (ESAC-Net). URL: http://ecdc. europa.eu/en/healthtopics/ antimicrobial_resistance/esac-net-database/Pages/ database.aspx Access Date:16 March 2017). In.

Evgenidou, E. N., Konstantinou, I. K., \& Lambropoulou, D. A. (2015). Occurrence and removal of transformation products of PPCPs and illicit drugs in wastewaters: A review. Science of the Total Environment, 505, 905-926.

Golovko, O., Kumar, V., Fedorova, G., Randak, T., \& Grabic, R. (2014). Seasonal changes in antibiotics, antidepressants/ psychiatric drugs, antihistamines and lipid regulators in a wastewater treatment plant. Chemosphere, 111, 418-426.

Grandclément, C., Seyssiecq, I., Piram, A., Wong-Wah-Chung, P., Vanot, G., Tiliacos, N., Roche, N., \& D. P. (2017). From the conventional biological wastewater treatment to hybrid processes, the evaluation of organic micropollutant removal: A review. Water Research, 111, 297-317.

Gulkowska, H. W., Leung, M. K., So, S., Taniyasu, N., Yamashita, L. W. Y., Yeung, B. J., Richardson, A. P., Lei, J. P., \& Giesy, P. K. S. L. (2008). Removal of antibiotics from wastewater by sewage treatment facilities in Hong Kong and Shenzhen, China. Water Research, 42, 395-403.

Hong, P.-Y., Al-Jassim, N., Ansari, M. I., \& RI, M. (2013). Environmental and public health implications of water reuse: antibiotics, antibiotic resistant bacteria, and antibiotic resistance genes. Antibiotics, 2, 367-399.

Jing, Z. Q., \& Cao, S. W. (2012). Combined application of UV photolysis and ozonation with biological aerating filter in tertiary wastewater treatment. International Journal of Photoenergy, 2012, 1-6.

Kang, A. J., Brown, A. K., Wong, C. S., Huang, Z., \& Yuan, Q. (2018). Variation in bacterial community structure of aerobic granular and suspended activated sludge in the presence of the antibiotic sulfamethoxazole. Bioresource Technology, 261, 322-328.

Lacey, C., Basha, S., Morrissey, A., \& Tobin, J. M. (2012). Occurrence of pharmaceutical compounds in wastewater process streams in Dublin, Ireland. Environmental Monitoring and Assessment, 184, 1049-1062.

NCBI. 2018. National Center for Biotechnology Information. PubChem Compound Database; Available from https://pubchem.ncbi.nlm.nih.gov/compound/54675776.

Östman, M., Björlenius, B., Fick, J., \& Tysklind, M. (2019). Effect of full-scale ozonation and pilot-scale granular activated carbon on the removal of biocides, antimycotics and antibiotics in a sewage treatment plant. Science of the Total Environment, 649, 1117-1123.

Pan, M., \& Chu, L. M. (2015). Adsorption and degradation of five selected antibiotics in agricultural soil. Science of the Total Environment, 545-546, 48-56.

Pan, M., \& Chu, L. M. (2016). Phytotoxicity of veterinary antibiotics on seed germination and root elongation of crops. Ecotoxicology and Environmental Safety, 126, 228-237.

Pan, M., \& Chu, L. M. (2017a). Fate of antibiotics in soil and their uptake by edible crops. Science of the Total Environment, 599-600, 500-512.

Pan, M., \& Chu, L. M. (2017b). Leaching behavior of veterinary antibiotics in animal manure-applied soils. Science of the Total Environment, 579, 466-473.
Pan, M., \& Chu, L. M. (2017c). Transfer of antibiotics from wastewater or animal manure to soil and edible crops. Environmental Pollution, 231, 829-836.

Pan, M., \& Chu, L. M. (2018). Occurrence of antibiotics and antibiotic resistance genes in soils from wastewater irrigation areas in the Pearl River Delta region, southern China. Science of the Total Environment, 624, 145-152.

Pan, M., Wong, K. C., \& Chu, L. M. (2014). Distribution of antibiotics in wastewater-irrigated soils and their accumulation in vegetables crops in the Pearl River Delta, southern China. Journal of Agricultural and Food Chemistry, 62, 11062-11069.

Papageorgiou, M., Kosma, C., \& Lambropoulou, D. (2016). Seasonal occurrence, removal, mass loading and environmental risk assessment of 55 pharmaceuticals and personal care products in a municipal wastewater treatment plant in Central Greece. Science of the Total Environment, 543, 547569.

Pereira, A. M., Silva, L. J., Meisel, L. M., Lino, C. M., \& Pena, A. (2015). Environmental impact of pharmaceuticals from Portuguese wastewaters: geographical and seasonal occurrence, removal and risk assessment. Environmental Research, 136, 108-119.

Sabri, N. A., van Holst, S., Schmitt, H., van der Zaan, B. M., Gerritsen, H. W., Rijnaarts, H. H. M., \& Langenhoff, A. A. M. (2020). Fate of antibiotics and antibiotic resistance genes during conventional and additional treatment technologies in wastewater treatment plants. Science of the Total Environment. https://doi.org/10.1016/j. scitotenv.2020.140199.

Santos LHMLM, Gros M, Rodriguez-Mozaz S, Delerue-Matos C, Pena A, Barceló D, Montenegro MCBSM (2013) Contribution of hospital effluents to the load of pharmaceuticals in urban wastewaters: identification of ecologically relevant pharmaceuticals. Sci Total Environ 461-462:302316

Suda, K. J., Hicks, L. A., Roberts, R. M., Hunkler, R. J., \& Taylor, T. H. (2014). Trends and seasonal variation in outpatient antibiotic prescription rates in the United States 2006 to 2010. Antimicrobial Agents and Chemotherapy, 58, 27632766.

Świątczak, P., \& Cydzik-Kwiatkowska, A. (2018). Performance and microbial characteristics of biomass in a full-scale aerobic granular sludge wastewater treatment plant. Environmental Science and Pollution Research International, 25, 1655-1669.

Van Boeckel, T. P., Brower, C., Gilbert, M., Grenfell, B. T., Levin, S. A., Robinson, T. P., Teillant, A., \& Laxminarayan, R. (2015). Global trends in antimicrobial use in food animals. Proceedings of the National Academy of Sciences of the United States of America, 112, 5649-5654.

Wang, S., Ma, X., Wang, Y., Du, G., Tay, J.-H., \& Li, J. (2019). Piggery wastewater treatment by aerobic granular sludge: granulation process and antibiotics and antibiotic-resistant bacteria removal and transport. Bioresource Technology, 273, 350-357.

Werner, N. L., Hecker, M. T., Sethi, A. K., \& Donskey, C. J. (2011). Unnecessary use of fluoroquinolone antibiotics in hospitalized patients. BMC Infectious Diseases, 11, 187.

Xu, J., Sheng, G.-P., Ma, Y., Wang, L.-F., \& Yu, H.-Q. (2013). Roles of extracellular polymeric substances (EPS) in the 
migration and removal of sulfamethazine in activated sludge system. Water Research, 47, 5298-5306.

Zhang, Q. Q., Ying, G. G., Pan, C. G., Liu, Y. S., \& Zhao, J. L. (2015). Comprehensive evaluation of antibiotics emission and fate in the river basins of china: source analysis, multimedia modeling, and linkage to bacterial resistance. Environmental Science and Technology, 49, 6772-6782.

Zheng, W., Wen, X., Zhang, B., \& Q. Y. (2019). Selective effect and elimination of antibiotics in membrane bioreactor of urban wastewater treatment plant. Science of the Total Environment, 646, 1293-1303.
Zuccato, E., Castiglioni, S., Bagnati, R., Melis, M., \& Fanelli, R. (2010). Source, occurrence and fate of antibiotics in the Italian aquatic environment. Journal of Hazardous Materials, 179, 2041-1048.

Publisher's Note Springer Nature remains neutral with regard to jurisdictional claims in published maps and institutional affiliations. 